\title{
Evaluation of Polycyclic Aromatic Hydrocarbons, Total Petroleum Hydrocarbons and Some Heavy Metals in Soils of Nnpc Oil Depot Aba Metropolis, Abia State, Nigeria.
}

\author{
E.C. Ogoko \\ Chemistry Department, School of Science and Technology, National Open University of Nigeria, PMB 80067, \\ Victoria Island, Lagos. Nigeria.
}

\begin{abstract}
Heavy metals concentrations were determined using Atomic Absorption Spectrophotometer (UNICAM SOLAR 32).Gas chromatography-flame ionization detector instrument was used in the detection and evaluation of levels of TPH while measurements of PAHs (total) concentration were performed with the aid of Chromatography mass spectrometer. Pollution indices such as contamination factor $(C F)$ and geoaccumulation index $\left(I_{\text {geo }}\right)$ as well as established guidelines of some selected countries and organizations on site contamination were used to compare results. Soil samples were obtained in triplicates and in soil depths of $0_{-}$ $10 \mathrm{~cm}, 10-20 \mathrm{~cm}$ and $20-30 \mathrm{~cm}$. The concentrations of $\mathrm{Zn}, \mathrm{Cu}, \mathrm{As}, \mathrm{Pb}, \mathrm{Cd}$ and $\mathrm{Hg}$ ranged between 112.30 to $202.10 \mathrm{mg} / \mathrm{kg}, 0.90$ to $5.80 \mathrm{mg} / \mathrm{kg}, 0.08$ to $2.50 \mathrm{mg} / \mathrm{kg}, 16.10$ to $32.3 \mathrm{mg} / \mathrm{kg}, 1.90$ to $11.78 \mathrm{mg} / \mathrm{kg}$ and 0.30 to 1.66 $\mathrm{mg} / \mathrm{kg}$ with mean concentrations of $157.00,3.84,1.40,22.30,7.02$ and $0.89 \mathrm{mg} / \mathrm{kg}$ respectively in soils of NNPC depot. Results of analysis of PAHs and TPH ranged from 6.30 to $7.40 \mathrm{mg} / \mathrm{kg}$ and 5120.50 to $24902.23 \mathrm{mg} / \mathrm{kg}$ respectively. Values of geo-accumulation index revealed that the study site was contaminated with $\mathrm{Pb}, \mathrm{Hg}$ and $C d$ (toxic metals). Established guidelines on assessment of site contamination soils from several countries used to compare this result demonstrated high levels of contamination of soils from NNPC depot Aba by $\mathrm{Hg}, \mathrm{Pb}, \mathrm{Cd}$, $P A H s$ and TPH compounds. The decreasing order of heavy metals concentration in the study site is presented as follows: $\mathrm{Zn}>\mathrm{Pb}>\mathrm{Cd}>\mathrm{Cu}>\mathrm{As}>\mathrm{Hg}$.
\end{abstract}

Key words: Oil depot, total petroleum hydrocarbon (TPH), soil contamination, heavy metals.

\section{Introduction}

Crude oil otherwise known as petroleum has continued to be the major income earner for Nigeria since the shift of attention from the agricultural sector to the oil sector. Nigeria crude oil is mainly the light grade type with low sulphur content, high concentration of naphthenic hydrocarbons, dye additives, antioxidants, alkanes, alkenes, alkynes and heavy metals.

Refined petroleum products are more toxic compared to crude oil due to alteration of metal speciation as well as addition of new metal in the matrix during refining process. Petroleum products are transported by the Nigeria National Petroleum Cooperation (NNPC) via pipes lines to several oil depots distributed all over the country. The petroleum products are in turn transported from these industrial oil and petroleum storage facilities to the end users through mobile tankers. Several sources of oil contamination of our environment have been identified; during exploration of crude oil, willful damage of pipes and pipelines for political and economic reasons as well as during loading and offloading of petroleum products in these depots. Others are deliberate discharge by refineries and petrochemical plants of effluent containing some residual hydrocarbon products without pretreatment, accidental spills from tankers during delivery as a result of collision and grounding as well as leakages from corroded and poorly maintained oil pipes.

Polycyclic aromatic hydrocarbons (PAHs) refer to a ubiquitous family of several chemically related environmental importunate organic compounds of various structures and with different levels of toxicity. Total petroleum hydrocarbon (TPH) is a generally accepted term which described a wide variety of derived petroleum compounds and it's by products. This parameter (TPH) measures the gross quantity of these petroleum hydrocarbon products present in the environment rather than seeking to measure individual component separately which could be tedious and non practicable.

The purpose of this work is to investigate the levels and the associated health hazards of PAHs, TPH and trace elements in soils of NNPC depot Aba and a reference site at the outskirts of Aba metropolis.

\section{Sample Collection and Preparation}

\section{Materials And Methods}

Soil samples were collected with auger at different soil depths in the range $0-10 \mathrm{~cm}, 10-20 \mathrm{~cm}$ and $20-$ $30 \mathrm{~cm}$ from soils within the vicinity of NNPC depot Aba and a reference site located at the outskirts of the city. 
The soil samples were homogenized in previously washed containers. After homogenization, portion of soil samples were kept into a properly washed amber bottle until use.

\section{Heavy Metal Determination}

One gram of sieved dried soil sample was weighed into a $100 \mathrm{ml}$ beaker and $10 \mathrm{ml}$ of nitric acid was added to the beaker. The content of the beaker was heated until dryness. $10 \mathrm{ml} \mathrm{HNO}$ and $\mathrm{HClO}_{4}$ was also added and the content of the beaker was heated until intense fuming. The solution was then allowed to cool and filtered. The residue was treated with hot $6 \mathrm{M} \mathrm{HCl}$ and the filterate made up to $50 \mathrm{ml}$. This was analyzed using Atomic Absorption Spectrophotometer (UNICAM SOLAR 32)

\section{Extraction Procedure for TPH}

Anhydrous sodium sulphate was added into an extracting bottle containing $10 \mathrm{~g}$ of previously homogenized soil samples and the mixture was stirred vigorously. $300 \mu \mathrm{g} / \mathrm{ml}$ of 1-chlorooctadecane (surrogate standard) was added to the sample. $30 \mathrm{ml}$ of dichloromethane was added in the extracting bottle containing the sample and the bottle tightly corked before transferring it to a mechanical shaker. The sample was allowed to settle for $1 \mathrm{~h}$ after agitation for 5 hour at room temperature in the mechanical shaker. The sample was filtered and the filtrate was allowed to concentrate to $1 \mathrm{ml}$ by evaporation overnight in a fume chamber. (LAWI, 2011; Alinnor and Nwachukwu, 2013).

\section{Analysis of TPH}

The separation and detection of compounds in the soil was carried out using Agilent 6890N Gas Chromatography- Flame Ionization Detector instrument. $3 \mu 1$ of concentrated sample that was previously eluted from column was injected into Gas chromatograph. The micro-syringe of GC was first rinsed with dichloromethane (blank) and further rinsed with the sample prior to sample analysis. Separation of sample into constituent compounds was achieved by injection of sample into the chromatographic column. The compounds after separation were passed through a flame ionization detector for detection and the amount of TPH was resolved at a particular chromatogram in mg/kg (LAWI, 2011; Cortes et al., 2012; Alinnor and Nwachukwu, 2013).

\section{Extraction Procedure And Analysis of PAHs}

The PAHs (total) was extracted and analysed according to the method described by Nor et al, (2013). $500 \mathrm{mg}$ of soil sample was dissolved in $25 \mathrm{ml} \mathrm{n}$-hexane and acetone 7:3 (v/v). The extractions were done with the pressurized microwave extraction system under control pressure, and over a period of about 40 minutes. The equipment was allowed to cool down at room temperature after extraction which was followed by filteration using whatman glass fibre filters and kept in $25 \mathrm{ml}$ universal bottles. The samples were concentrated by use of rotary evaporator to $1 \mathrm{ml}$.

Measurement of PAHs concentrations was done by the use of chromatography mass spectrometer equipped (Perkin Elmer Clarus) with elite column. The carrier gas was helium and a constant flow rate of $1 \mathrm{ml} / \mathrm{min}$ was maintained and the amount of PAHs was resolved at a particular chromatogram in $\mathrm{mg} / \mathrm{kg}$.

\section{Computation of Pollution Indices}

Contamination Factor $(\mathrm{CF})$ is defined as the degree of contamination with respect to measured background values of a geologically similar and uncontaminated area (or the average crustal composition of the metal).

$\mathrm{CF}$ is therefore expressed, $\mathrm{CF}=\mathrm{C}_{\mathrm{m}} / \mathrm{B}_{\mathrm{m}}$

Where $\mathrm{CF}$ is concentration factor, $\mathrm{C}_{\mathrm{m}}$ is metal concentration and $\mathrm{B}_{\mathrm{m}}$ is the background value of the metal. Geoaccumulation Index ( $\left.\mathbf{I}_{\text {geo }}\right)$ is a quantitative tool which expresses the extent of metal accumulation in sediments. It was proposed by Mueller (1979) and has been very useful in evaluating the degree of metal contamination in both aquatic and terrestrial environment (Elias et al., 2011; Tijani et al., 2004).

$\mathbf{I}_{\text {geo }}=\operatorname{In}\left[\left(\mathrm{C}_{\mathrm{m}}\right) / 1.5 \mathrm{x}\left(\mathrm{B}_{\mathrm{m}}\right)\right]$

where $C_{m}$ and $B_{m}$ is as defined above, 1.5 is a correction factor due to variation in the background concentration as a result of lithologic differences. Geo-accumulation index scale has seven descriptive classes (0 to 6) ranging from practically unpolluted to very strongly polluted.

\section{Results And Discussion}

The results of heavy metal content of soil of NNPC depot and the reference site are presented in Tables 1 and 2 respectively. 
Table 1: Levels of heavy metal in soil profile at NNPC depot Aba (mg/kg)

\begin{tabular}{|c|c|c|c|c|c|c|c|}
\hline \multicolumn{2}{|c|}{ Depth $(\mathrm{cm})$} & $\mathrm{Pb}$ & $\mathrm{Cd}$ & As & $\mathrm{Hg}$ & $\mathrm{Cu}$ & $\mathrm{Zn}$ \\
\hline \multirow[t]{4}{*}{$0-10$} & Mean & 32.30 & 11.78 & 2.50 & 1.66 & 5.80 & 202.10 \\
\hline & Max & 43.20 & 14.80 & 3.50 & 2.15 & 6.80 & 230.00 \\
\hline & Min & 21.40 & 8.76 & 1.50 & 1.21 & 4.60 & 174.90 \\
\hline & SD & 11.20 & 3.03 & 1.18 & 0.43 & 0.92 & 27.56 \\
\hline \multirow{4}{*}{$10-20$} & Mean & 18.60 & 7.39 & 1.63 & 0.71 & 4.82 & 156.50 \\
\hline & Max & 21.60 & 11.40 & 2.10 & 0.91 & 6.32 & 174.50 \\
\hline & Min & 15.80 & 5.12 & 1.10 & 0.50 & 3.32 & 138.00 \\
\hline & SD & 2.46 & 2.76 & 0.49 & 0.21 & 1.24 & 17.10 \\
\hline \multirow[t]{4}{*}{$20-30$} & Mean & 16.10 & 1.90 & 0.08 & 0.30 & 0.90 & 112.30 \\
\hline & $\operatorname{Max}$ & 20.10 & 2.30 & 0.10 & 0.40 & 1.20 & 128.00 \\
\hline & Min & 12.10 & 1.50 & 0.06 & 0.20 & 0.60 & 96.60 \\
\hline & SD & 4.16 & 0.48 & 0.02 & 0.19 & 0.31 & 15.81 \\
\hline
\end{tabular}

Table 1 revealed a stepwise decrease in lead content across soil profile studied. Lead concentration ranged between $16.1 \mathrm{mg} / \mathrm{kg}$ to $32.3 \mathrm{mg} / \mathrm{kg}$ with a mean concentration of $22.3 \mathrm{mg} / \mathrm{kg}$. These values were higher than those obtained in Table 2, for control samples and also higher than $15.1 \mathrm{mg} / \mathrm{kg}$ reported by Adelekan and Abegunde(2011) as well as $14.13 \mathrm{mg} / \mathrm{kg}$ reported by Babantude et al (2014). The $\mathrm{Pb}$ values in the study area were however lower than value $(76.92 \mathrm{mg} / \mathrm{kg}$ ) of Okunola et al (2007), $47.8 \mathrm{mg} / \mathrm{kg}$ of Sitkol et al (2004) as well as USEPA (2008) and NEPCA (2010) relative relaxed criteria of $400 \mathrm{mg} / \mathrm{kg}$ and $300 \mathrm{mg} / \mathrm{kg}$ respectively. The values of calculated geo-accumulation index $\left(\mathbf{I}_{\text {geo }}\right)$ were presented in Table 3. These values showed a slight contamination of lead in soils of NNPC depot at depth of 0-10 cm whereas depths of 10-20 cm and $20-30 \mathrm{~cm}$ remained uncontaminated. Inhalation and ingestion are the two main routes of $\mathrm{Pb}$ exposure to humans and other vertebrates. Lead finds its way and accumulates in the brain and could lead to death, gastrointestinal tract, kidney as well as central nervous system disorder.Other health risks associated with lead include impaired growth, loss of memory, nausea, insomnia and anorexia (NSC, 2009).

Table 2: Levels of heavy metal in soil profile at control site $(\mathrm{mg} / \mathrm{kg})$.

\begin{tabular}{rlrlllrr} 
Depth $(\mathrm{cm})$ & $\mathrm{Pb}$ & $\mathrm{Cd}$ & $\mathrm{As}$ & $\mathrm{Hg}$ & $\mathrm{Cu}$ & $\mathrm{Zn}$ \\
\hline \multirow{3}{*}{$0-10$} & & & & & & & \\
& Mean & 0.020 & 0.005 & 0.002 & $\mathrm{ND}$ & 0.900 & 106.230 \\
& Max & 0.030 & 0.007 & 0.003 & $\mathrm{ND}$ & 1.100 & 126.000 \\
& Min & 0.010 & 0.003 & 0.001 & ND & 0.700 & 86.340 \\
& SD & 0.010 & 0.002 & 0.001 & ND & 0.200 & 19.830 \\
$10-20$ & & & & & & & \\
& Mean & 0.007 & 0.002 & ND & ND & 0.059 & 123.500 \\
& Max & 0.008 & 0.003 & ND & ND & 0.070 & 133.000 \\
& Min & 0.006 & 0.001 & ND & ND & 0.048 & 117.000 \\
& SD & 0.001 & 0.001 & ND & ND & 0.011 & 8.047 \\
& & & & & & & \\
& Mean & 0.004 & 0.001 & ND & ND & 0.030 & 54.230 \\
& Max & 0.005 & 0.001 & ND & ND & 0.040 & 64.200 \\
& Min & 0.003 & 0.001 & ND & ND & 0.020 & 44.260 \\
& SD & 0.001 & 0.000 & ND & ND & 0.010 & 9.967 \\
\hline
\end{tabular}

Table 1 also revealed a gradual decrease in the concentrations of $\mathrm{Zn}, \mathrm{Cu}$ and As across soil layers of the profile. Concentrations of $\mathrm{Zn}, \mathrm{Cu}$ and As ranged between 112.30 to $202.10 \mathrm{mg} / \mathrm{kg}, 0.90$ to $5.80 \mathrm{mg} / \mathrm{kg}$ and 0.08 to 2.5 $\mathrm{mg} / \mathrm{kg}$ with mean concentrations of $157.00,3.84$ and $1.40 \mathrm{mg} / \mathrm{kg}$ respectively in soils of NNPC depot. These values were much greater than those recorded for control samples as shown in Table 2, indicating some level of accumulation of these trace metals on soils within the vicinity of NNPC depot Aba. The levels of Cu determined in the study area were higher than value $(2.78 \mathrm{mg} / \mathrm{kg})$ of Bai et al (2008) but lower than $22.14 \mathrm{mg} / \mathrm{kg}$ and 47.0 
$\mathrm{mg} / \mathrm{kg}$ reported by Babatunde et al (2014) and Fisseha et al (2008) respectively. The mean value of $\mathrm{Zn}$ in this present study was well above 0.03 to $5.5 \mathrm{mg} / \mathrm{kg}$ and $25.06 \mathrm{mg} / \mathrm{kg}$ reported by Mitsios et al (2005) and Srinivas et al (2009) respectively. Other values recorded by Okunola et al (2007) and Sitkol et al (2004) were 237.96 $\mathrm{mg} / \mathrm{kg}$ and $761 \mathrm{mg} / \mathrm{kg}$ respectively, which were considerably higher than those values obtained in this study. The calculated values of geo-accumulation index do not indicate any contamination level of samples of NNPC depot studied by $\mathrm{Zn}, \mathrm{Cu}$ and As. Arsenic causes skin damage, increase risk of cancer, and problem with circulatory system (Scragg, 2006).Copper and zinc are essential macronutrient required for both plants and animal health. High doses of $\mathrm{Cu}$ are associated with anaemia, liver and kidney damage as well as irritation of both stomach and intestine (Bjuhr, 2007).Excess doses of $\mathrm{Zn}$ in the soil retard the breakdown of organic matter by influencing the activity of microorganism and earthworm (Greany,2005).

The values of Cadmium recorded in the study area ranged between 1.90 to $11.78 \mathrm{mg} / \mathrm{kg}$ with a mean concentration of $7.02 \mathrm{mg} / \mathrm{kg}$. Cadmium concentrations at the control site ranged between 0.001 to $0.005 \mathrm{mg} / \mathrm{kg}$ and were well below the values obtained from samples at the vicinity of NNPC depot. The mean Cd value in the study area was relatively close to $9.11 \mathrm{mg} / \mathrm{kg}$ recorded from soils within the vicinity of NNPC depot Jos, Nigeria by Babatude et al (2014) but significantly higher than $0.60 \mathrm{mg} / \mathrm{kg}$ obtained at automobile mechanic site in Benue, north-central Nigeria by Pam et al (2013). The calculated values of CF and geo-accumulation index in Table 3 revealed that soils of the NNPC depot were strongly contaminated by Cadmium. Bioaccumulation of $\mathrm{Cd}$ in the Kidneys leads to kidney dysfunction.

TABLE 3: Metal contamination factor and geo-accumulation index of metals in soil profile at both sites.

\begin{tabular}{cccccc}
\hline \multirow{2}{*}{ Parameter } & Depth $(\mathrm{cm})$ & \multicolumn{2}{c}{ NNPC DEPOT } & \multicolumn{2}{c}{ CONTROL SITE } \\
& & $\mathrm{CF}$ & $\mathrm{I}_{\text {geo }}$ & $\mathrm{CF}$ & $\mathrm{I}_{\text {geo }}$ \\
\hline $\mathrm{Pb}$ & $0-10$ & 2.019 & 0.297 & 0.0013 & -7.0901 \\
& $10-20$ & 1.163 & -0.255 & 0.0004 & -8.1399 \\
& $20-30$ & 1.138 & -0.399 & 0.0003 & -8.6995 \\
$\mathrm{Cd}$ & $0-10$ & 78.53 & 5.855 & 0.0333 & -1.9095 \\
& $10-20$ & 49.27 & 5.388 & 0.0133 & -2.8260 \\
& $20-30$ & 12.67 & 4.031 & 0.0067 & -3.5190 \\
$\mathrm{As}$ & $0-10$ & 0.500 & -2.708 & 0.0004 & -9.8390 \\
& $10-20$ & 0.326 & -3.135 & $\mathrm{ND}$ & $\mathrm{ND}$ \\
& $20-30$ & 0.016 & -6.150 & $\mathrm{ND}$ & $\mathrm{ND}$ \\
$\mathrm{Hg}$ & $0-10$ & 20.75 & 2.627 & $\mathrm{ND}$ & $\mathrm{ND}$ \\
& $10-20$ & 8.875 & 1.777 & $\mathrm{ND}$ & $\mathrm{ND}$ \\
& $20-30$ & 3.750 & 0.916 & $\mathrm{ND}$ & $\mathrm{ND}$ \\
$\mathrm{Cu}$ & $0-10$ & 0.083 & -2.897 & 0.0129 & -4.7593 \\
& $10-20$ & 0.069 & -3.081 & 0.0008 & -7.4842 \\
& $20-30$ & 0.013 & -4.862 & 0.0004 & -8.1605 \\
$\mathrm{Zn}$ & $0-10$ & 1.531 & -4.862 & 0.8048 & -5.5055 \\
& $10-20$ & 1.186 & -5.118 & 0.9356 & -5.3548 \\
& $20-30$ & 0.851 & -5.450 & 0.4108 & -6.1778 \\
& & & & \\
\hline
\end{tabular}

Mercury was found to be present in all the soil samples from NNPC depot with highest concentration of 1.66 $\mathrm{mg} / \mathrm{kg}$ and lowest concentration of $0.30 \mathrm{mg} / \mathrm{kg}$. The result revealed a steady downward decrease in concentration of mercury across depths studied. Samples from NNPC depot recorded higher values of $\mathrm{Hg}$ concentration than samples from reference site. The value of $\mathrm{Hg}$ obtained at depth of 0 to $10 \mathrm{~cm}$ was above the NEPC, (1999) recommended limit of $1.0 \mathrm{mg} / \mathrm{kg}$ indicating site contamination by $\mathrm{Hg}$. The geo-accumulation index also clearly indicated that NNPC depot soils were moderately contaminated with mercury. Mercury is mainly toxic in its soluble and volatile alkylated forms and if it accumulates in the soil or agricultural crops above 0.006ppm could cause permanent damage to the brain, lungs and kidneys (Scragg, 2006).

The results obtained from the analysis of Total Petroleum Hydrocarbons (TPH) and total Polycyclic Aromatic Hydrocarbons (PAH) in soils within the vicinity of NNPC depot and control site were presented in Tables 4 and 5 respectively. 
Table4: Total Petroleum Hydrocarbons (TPH) and Polycyclic Aromatic Hydrocarbons (PAH) in soils within the vicinity of NNPC depot $(\mathrm{mg} / \mathrm{kg})$.

\begin{tabular}{llrr} 
Depth $(\mathbf{c m})$ & PAH $(\mathbf{m g} / \mathbf{k g})$ & TPH $(\mathbf{m g} / \mathbf{g}$ \\
\hline & & & \\
$0-10$ & Mean & 7.40 & 24902.23 \\
& Max & 8.10 & 25000.20 \\
& Min & 6.40 & 24800.23 \\
& SD & 0.89 & 99.89 \\
$10-20$ & & & \\
& Mean & 6.47 & 11349.00 \\
& Max & 7.40 & 11379.01 \\
& Min & 5.74 & 11329.00 \\
& SD & 0.85 & 26.46 \\
& & & \\
& mean & 6.30 & 5120.50 \\
& Max & 6.90 & 5190.60 \\
& Min & 5.70 & 5050.40 \\
& SD & 0.60 & 70.51 \\
\hline
\end{tabular}

Table 5: Results of Total Petroleum Hydrocarbons (TPH) and Polycyclic Aromatic Hydrocarbons (PAHs) in soils at the control site $(\mathrm{mg} / \mathrm{kg})$.

\begin{tabular}{llll} 
Depth $(\mathbf{c m})$ & PAH $(\mathbf{m g} / \mathbf{k g})$ & TPH $(\mathbf{m g} / \mathbf{k g})$ \\
\hline \multirow{3}{*}{$0-10$} & Mean & 0.050 & 0.090 \\
& Max & 0.060 & 0.105 \\
& Min & 0.045 & 0.075 \\
& SD & 0.009 & 0.015 \\
$10-20$ & & & \\
& Mean & 0.003 & 0.012 \\
& Max & 0.004 & 0.015 \\
& Min & 0.002 & 0.010 \\
$20-30$ & SD & 0.001 & 0.003 \\
& & & \\
& mean & 0.090 & 0.110 \\
& Max & 0.100 & 0.130 \\
& Min & 0.080 & 0.090 \\
& SD & 0.010 & 0.020 \\
\hline
\end{tabular}

The results of total polycyclic aromatic hydrocarbon in the study site recorded elevated values which ranged between 6.3 to $7.4 \mathrm{mg} / \mathrm{kg}$ as compared with 0.003 to $0.09 \mathrm{mg} / \mathrm{kg}$ obtained at the control site. Total PAHs concentration obtained in this study were higher than the recommended levels of $1000 \mu \mathrm{g} / \mathrm{kg}, 1500 \mu \mathrm{g} / \mathrm{kg}$ and $5 \mathrm{mg} / \mathrm{kg}$ imposed by soil clean-up guide lines from Denmark, Netherlands and Australia respectively (DEPA, 2002; MHSPEN, 2000; ANZECC, 1992).The high PAHs content of soil samples indicates contamination of the study site.

Inhalation, ingestion and dermal contact are the primary routes of exposure of PAHs to humans. PAHs are extremely toxic with excellent capability to stimulate health effects such as nausea, vomiting, eye irritation, diarrhea and confusion (short term effects).Other health effects (long term) include immune function suppression, cataracts, kidney and liver damage, skin inflammation, asthma amongst others. Generally, mixtures of PAHs are known to cause carcinogenic, genotoxic, teratogenic effects and are potential immunosuppressant. The mean TPH concentrations of soil samples obtained within the vicinity of NNPC depot are 24902.23, 11349 and $5120.5 \mathrm{mg} / \mathrm{kg}$ at depths of $0-10,10-20$ and $20-30 \mathrm{~cm}$ respectively. The TPH concentrations were well above $0.09,0.012$ and $0.11 \mathrm{mg} / \mathrm{kg}$ obtain at control site across depths of $0-10,10-20$ and 20-30 cm respectively and also higher than DPR.(2002) and NSW.(2009) recommended maximum permissible limit of $1000 \mathrm{mg} / \mathrm{kg}$ 
indicating high level contamination of soil samples from study site. Alinnor and Nwachukwu,(2013) reported that soil samples in Rivers State, Nigeria were contaminated with TPH concentrations of 1534.7, 1438.0 and $1651.0 \mathrm{mg} / \mathrm{kg}$ at depths of 0.0 to $0.5 \mathrm{~m}, 0.5$ to $1.0 \mathrm{~m}$ and 1.0 to $2.0 \mathrm{~m}$ respectively, which are much lower than values obtained in this study. According to Iturbe et al. (2004), the soil of coastal Mexican refinery was heavily contaminated with hydrocarbons with detectable TPH concentration of $130000 \mathrm{mg} / \mathrm{kg}$. This value was higher than those recorded at soils from the study site (NNPC depot) in this work. TPH compounds are generally carcinogenic, Genotoxic, teratogenic and immunotoxic in nature.

\section{Conclusion And Recommendation}

The results of this study revealed elevated values of $\mathrm{Pb}, \mathrm{Hg}, \mathrm{Cd}$, PAHs and $\mathrm{TPH}$ in the soil samples of NNPC depot when compared with the control samples. Values of geo-accumulation index indicated contamination of the study site by $\mathrm{Pb}, \mathrm{Hg}$ and $\mathrm{Cd}$ (toxic metals). Established guidelines of several countries used to compare these results demonstrated high levels and contamination of soils of the study site by these toxicants. Other elements such as $\mathrm{As}, \mathrm{Zn}$ and $\mathrm{Cu}$ were also detected in the soil samples at levels which does not pose treat to health. Remediation and cleanup measures should be adopted and periodically carried out on soils contaminated by toxicants in order to reduce or circumvent associated health hazards. Besides, reclamation of these soils from toxicants would maximize the land resources for agricultural operations and ultimately guarantee food safety.

\section{References}

[1]. Laboratory Analytical Work Instruction (LAWI) for the Determination of Total Petroleum Hydrocarbon in Soil/Sediment/Sludge in Gas Chromatography. (2011).Published by Fugro (Nig.) Ltd. 3:9.

[2]. Alinnor I. J. and Nwachukwu M. A. (2013) Determination of total petroleum hydrocarbon in Soil and groundwater samples in some communities in Rivers State, Nigeria. J. Environmental Chemical and Ecotoxicology. 5(11):292-297.

[3]. Cortes J.E, Suspes A, Roa S, Gonzalez C, Castro H. E (2012).Total petroleum hydrocarbon by Gas Chromatography in Colombia waters and soil. American Journal of Environmental Science. 8(4):396-402.

[4]. Nor A.F.M.K. and Suhaimi A. (2013) Hazards due to polycyclic aromatic hydrocarbons (PAHs) and heavy metals at the closed KubangBadak landfill, Selangor. International Journal of Environmental Monitoring and Analysis. 1(2):71-77.

[5]. Muller, G., (1969). Index of geoaccumulation in sediments of the Rhine River. Geol. J. 2, $109-118$.

[6]. Elias, P., and Gbagegesin A. (2011). Spatial relationships of urban land use soils and heavy metal concentrations in Lagos mainland. J. Appl. Sci. Environ. Manage, 15(2):391-399.

[7]. Tijani, M. N., Jinno, K., \&Hiroshiro, Y. (2004).Environmental impact of heavy metal distribution in water and sediment of Ogunpa River, Ibadan area, southwestern Nigeria.J. Min. Geol., 40(1):73-83.

[8]. Adelekan B. A. and Adegunde K. D. (2011). Heavy metals contamination of soil and groundwater at automobile mechanic villages in Ibadan, Nigeria. International Journal of the Physical Sciences. 6(5): 1045-1058. http//www.academicjournals.org.

[9]. Babatunde O. A.; A. O. Oyewale and Steve P. I (2014). Bioavailability of Trace Element in Soils around Nnpc Oil Depot Jos, Nigeria. Journal Of Environmental Science, Toxicology And Food Technology (IOSR-JESTFT) Volume 8, PP 47-56.

[10]. Okunola O. J., Uzairu A. and Ndukwe G. (2007). Levels of trace metals in soil and vegetation along major and minor roads in metropolitan city of kaduna, Nigeria. African Journal of Biotechnology. 6(14):1703-1709.

[11]. Sitkol L. R., Zawisza B., Jurczyk J., Buhl F. and Zielonka U. (2004). Determination of High Zn and Pb Concentrations in Polluted Soils Using Energy-Dispersive X-ray Fluorescence Spectrometry. Polish Journal of Environmental Studies. 13(1):pp. 91-96.

[12]. United States Environmental Protection Agency, USEPA (2008). Allowable Limits for Lead in Soil. www.epa.gov/lead/pubs/leadhaz.htm

[13]. National Environment Protection Council of Australia, NEPCA, (2010). Limits of Heavy Metals in Soils. Available online at www.newzealand.govt.nz

[14]. NSC, Lead Poisoning, National Safety Council, (2009) http:// www.nsc.org/news resources/Resources/Documents/Lead Poisoning.pdf.

[15]. Bai J., Cui B., Wang Q., Gao H. and Ding Q. (2008). Assessment of heavy metal contamination of road side soils in Southwest China. Stoch. Environ. Res. Risk Ass. DOI 10.1007/s00477-008-0219-5.

[16]. Fisseha I., Jorn B. and Mats O. (2008). The fate and bioavailability of some trace elements applied to two vegetable farms in Addis Ababa. African Journal of Agricultural Research. 3(11):797-807.

[17]. Mitsios I. K., Golia E. E. and Tsadilas C. D. (2005). Heavy Metal Concentrations in Soils and Irrigation Waters in Thessaly Region, Central Greece. Journal of Soil Science and Plant Analysis. 36 (4-6): 487-501.

[18]. Srinivas N., Ramakrishna R. S. and Suresh K. K. (2009). Trace Metal Accumulation in vegetables grown in industrial and semi-urban areas- A case study. Applied Ecology and Environmental Research. 7(2):131-139.

[19]. A. Scragg, (2006). Environmental Biotechnology, Oxford University Press, Oxford, UK, 2nd edition,

[20]. J. Bjuhr, Trace Metals in Soils Irrigated with Waste Water in a Periurban Area Downstream Hanoi City, Vietnam, Seminar Paper, Institution enformarkvetenskap, Sveriges lantbruksuniversitet (SLU), Uppsala, Sweden, 2007.

[21]. K. M. Greany, (2005). An assessment of heavy metal contamination in the marine sediments of Las Perlas Archipelago, Gulf of Panama, M.S. thesis, School of Life Sciences Heriot-Watt University, Edinburgh, Scotland, Aloysius A. Pam, Rufus Sha'Ato 1 and John O.Offem,(2013). Contributions of Automobile Mechanic Sites to Heavy Metals in Soil: A Case Study of North Bank Mechanic Village Makurdi, Benue State, Central Nigeria. Journal of Chemical, Biological and Physical Science 3 (3); $2337-2347$.

[22]. National Environmental Protection Measurement of Australia, NSW, (1999).

[23]. Iturbe R, Flores R.M, Flores C.R, Torres L.G. (2004). TPH contaminated Mexican refinery soil: Heaith risk assessment and the first year of changes. Environ. Monit. and Assess. 91(1-3):237-255.

[24]. Department of Petroleum resources (DPR). (2002). Environmental guidelines and standards for the petroleum industry in Nigeria (EGASPIN).

[25]. The National Environment Protection (Assessment of Site Contamination) Measure 1999 (NEPC 1999) are replaced as of 16 May 2013 by references to the National Environment Protection (Assessment of Site Contamination) Measure 1999 (April, 2013). 
[26]. Danish Environmental Protection Agency, "Guideline on remediation of contaminated sites, 'Danish Environmental Protection Agency (DEPA), Demark, 2002.

[27]. Ministry of Housing Spatial Planning and Environment, "Circular on target values and intervention values for soil remediation," Ministry of Housing Spatial Planning and Environment, Netherlands (MHSPEN), 2000.

[28]. The Australian Water Quality Guidelines for Fresh and Marine Waters (ANZECC, November 1992). 